\title{
A COMPARATIVE STUDY OF FINITE JOURNAL BEARING IN LAMINAR AND TURBULENT REGIMES USING CFD (COMPUTATIONAL FLUID DYNAMIC)
}

\author{
Susilowati ${ }^{1,2}$, Mohammad Tauviqirrahman ${ }^{2}$, J. Jamari ${ }^{2}$, Athanasius P. Bayuseno ${ }^{2}$ \\ and Muchammad ${ }^{3}$ \\ ${ }^{1}$ Universitas Pembangunan Nasional "Veteran" Jawa Timur, Surabaya-Indonesia \\ ${ }^{2}$ Universittas Diponegoro, Semarang-Indonesia \\ ${ }^{3}$ University of Twente, The Netherlands \\ E-mail: zuzisukasno@gmail.com
}

\begin{abstract}
In this paper, an investigation of hydrodynamic performance for journal bearing lubricated by thin film is performed by three-dimensional CFD (computational fluid dynamic). Two regimes, i.e. laminar and turbulent regimes are of main interest. The sliding velocity was varied from 3000, 5000 and 10000. The numerical simulation shows that the velocity magnitude of the journal has a strong effect on the hydrodynamic pressure. In addition, it is found that an appropriate modelling of flow regime affects the predicted lubrication performance. From the overall analysis, both using laminar and turbulent regimes, the distribution of static hydrodynamic pressure shows a similar trend. It is also found that at the beginning of the contact, the static pressure is low, and then, it gradually increases to the highest point, and finally drops significantly.
\end{abstract}

Keywords: Computational fluid dynamic (CFD), journal bearing, lubrication, turbulent

\section{INTRODUCTION}

Recently, a thin film lubricated journal bearing has attracted much attention. Following the progress in numerical analysis and technology, many researchers began to use commercial computational fluid dynamics (CFD) program in their investigations. The main advantage of CFD code is that it uses the full Navier Stokes equations and provides a solution to the flow problem based on finite volume method (Panday et al., 2012). Therefore, the CFD methods are applicable in very complex geometries.

Gertzos et al., (2008) worked on CFD method of lubricated journal bearing by Bingham lubricant. They solved Navier-Stokes equations by using the FLUENT package and compared the results of the developed 3-D CFD model with theoretical and experimental results of previous investigations, for both Newtonian and Bingham lubricants, and found to be in a very good agreement.

Stefani and Rebora (2009) worked on using Quasi3D mass-energy-conserving method by extending a previous mass and energy-conserving algorithm. The proposed method produced temperature profiles in a good agreement with the experimental results, whenever consistent boundary conditions were induced. Taking into account the thermal deformations of the kinematic pair, it leads us to improve the reliability of the model.

Gururajan and Prakash (2002) investigated the effect of surface roughness in a narrow porous journal bearing. It was shown that for a smooth case, the results based on an approximate analysis could be safely used for thin-walled bearings of low permeability.

Peng et al., (2007) developed a new form of the Reynolds equation. The new Reynolds equation for the lubricating film was solved by using Finite Volume (FV) discretization. According to the numerical solution, the journal squeeze effect and the pad rotation effect on film force were discussed.
Basri and Gethin (1990) principally described a theoretical analysis of the thermal behavior of offset half, orthogonally displaced, three-lobe and four-lobe bearing geometries. Murthy et al., (1983) dealt with the analysis of a special hydrodynamic bearing incorporated in a precision cylindrical grinding machine.

For unsteady analysis, Krasowski (2011) studied laminar flow during periodic and unperiodic perturbations of bearing load. It was found that perturbations mostly occured during the starting and stopping of the machine. Reynolds Equation solution for unsteady laminar newtonian flow of lubricated oil was presented to enable initial opinion to hydrodynamic pressure and velocity distribution as a basic slide bearing operating parameter.

Sharma et al., (2011) studied on film lubrication performance to a certain degree. The finite element method was theoretically studied with respect to the performance of four- containers hydrostatic tapered bearing system.

Roy (2009) investigated thermo-hydrodynamic analysis of oil journal bearing and made a comparison at five different feeding locations of an axial grooved. Reynolds equation was solved simultaneously along with the energy equation and heat conduction equation in bush and shaft.

Based on the survey of literature, the analysis mostly neglects the cavitation phenomena which may be present in analysis. In addition, laminar regime is a particular interest. This paper is aimed at analyzing the journal bearing using laminar and turbulent approaches by employing CFD. This method is applicable by using cavitation model, hence it is more realistic to simulate the situation.

\section{METHODOLOGY}

This research uses laminar and turbulent regimes and makes a comparison between them to investigate 
which best model to represent the phenomena. The sliding velocities used are $3000 \mathrm{rpm}, 5000 \mathrm{rpm}$, and $10000 \mathrm{rpm}$.

Operational pressure is set to $101325 \mathrm{~Pa}$. Whereas, the ratio of $\mathrm{L} / \mathrm{D}$ is 0.25 . The $3-\mathrm{D}$ simulation model is developed by using the CFD package FLUENT.

\section{Mathematical model}

The equation for mass conservation, or the continuity equation, can be writen as:

$$
\frac{d \rho}{d t}+\nabla \cdot(\rho \vec{v})=0
$$

Eq.(1) is the general form of the mass conservation equation, and it is valid for both incompressible and compressible flows. Momentum conservation equations (the Navier Stokes equations) Conservation of momentum in an inertial (nonaccelerating) reference frame is described by:

$$
\frac{\partial}{\partial t}(\rho \vec{\vartheta})+\nabla \cdot(\rho \cdot \vec{\vartheta} \cdot \vec{\vartheta})=-\nabla \rho+\nabla \cdot(\overline{\bar{\tau}})+\rho \vec{g}+\vec{F}
$$

Where $\rho \vec{v}$ and $\vec{F}$ are the gravitational and external body forces, respectively. The stress tensor $\tau$ is given by

$$
\overline{\bar{\tau}}=\mu_{\mathrm{a}}\left[\left(\nabla \vec{\vartheta}+(\nabla \vec{\vartheta})^{T}\right)-\frac{2}{3} \cdot \nabla\right] \cdot \vec{\vartheta} \bar{I}
$$

where the second term on the right hand side is the effect of volume dilation. All investigations that are referred in this work solve the fundamental Reynolds Eq. (4), or a modified form of (4) that takes into account the equations describing the non-Newtonian lubricant,

$\nabla \cdot\left(\frac{h^{3}}{12 \mu} \cdot \Delta \rho\right)=\nabla \cdot(h \bar{U})-V$

\section{RESULTS}

The simulation results are divided into main categories, i.e. laminar and turbulent analyses. This comparison would give which best model in predicting the characteristic of lubricated bearing.

\section{Laminar Approach}

Figures 1-6 show the static hydrodynamic pressure of the lubricant in the journal bearing by varying the rotational speed of 3000,5000 , and $10000 \mathrm{rpm}$ for the laminar analysis. For the laminar approach for the rotational speed of $3000 \mathrm{rpm}$ (Figures 1 and 2) from the static pressure, it can be concluded that zero pressure is present at inlet area. The score ranges around 640 to 8000 $\mathrm{Pa}$. Whereas, for the rotational speed of $5000 \mathrm{rpm}$ laminar (Figures 3 and 4), the result is almost the same with the rotational speed of $3000 \mathrm{rpm}$. The only difference is the lower score range of contour static. This also applies for the rotational speed of $10000 \mathrm{rpm}$ (Figures 5 and 6). The result is the same with the rotational speed of $3000 \mathrm{rpm}$ and 5000 rpm laminar.

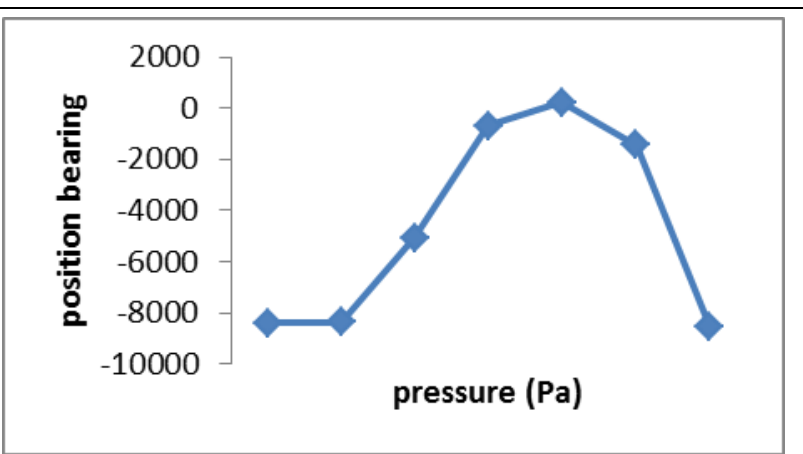

Figure-1. Static pressure distribution for laminar condition at $3000 \mathrm{rpm}$.

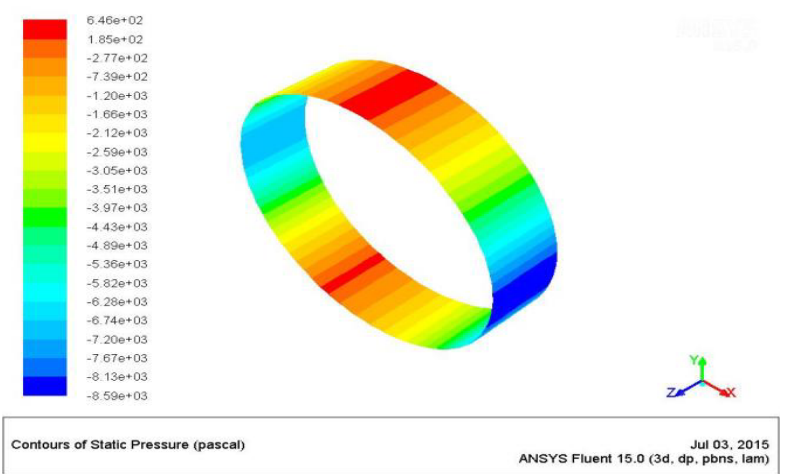

Figure-2. Static pressure contour of lubricant for 3000 rpm at laminar regime.

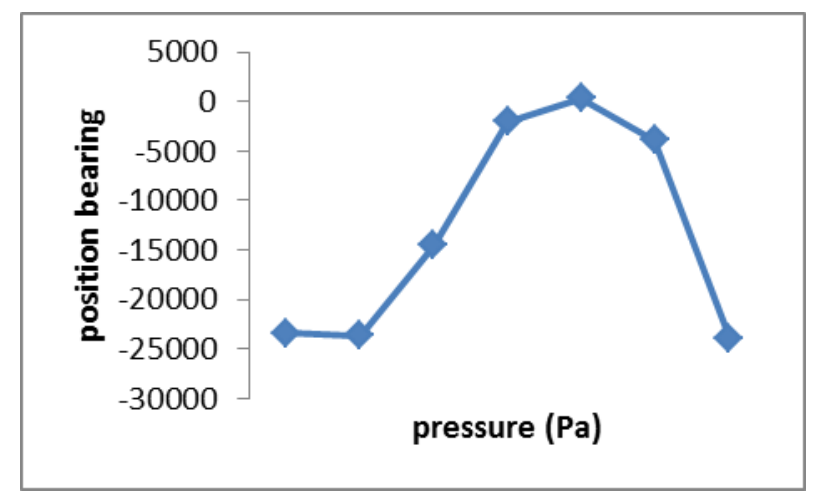

Figure-3. Static pressure distribution for laminar condition at $5000 \mathrm{rpm}$.

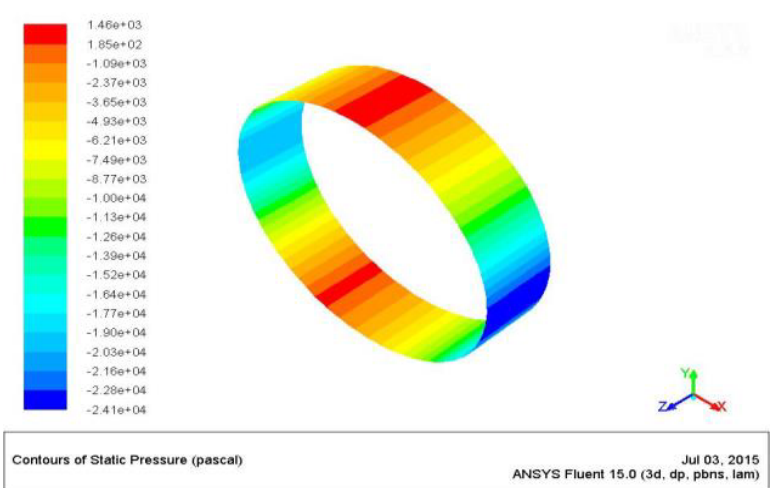

Figure-4. Static pressure contour of lubricant for 5000 rpm at laminar regime. 


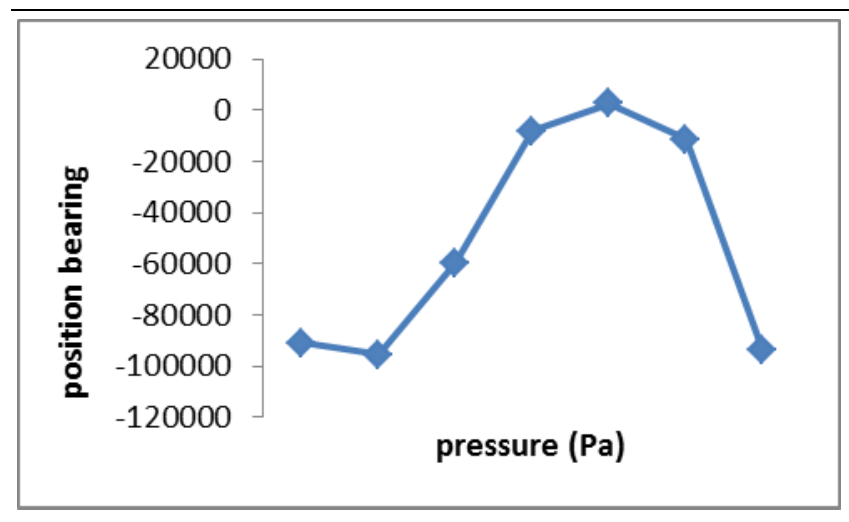

Figure-5. Static pressure distribution for laminar condition at $10000 \mathrm{rpm}$.

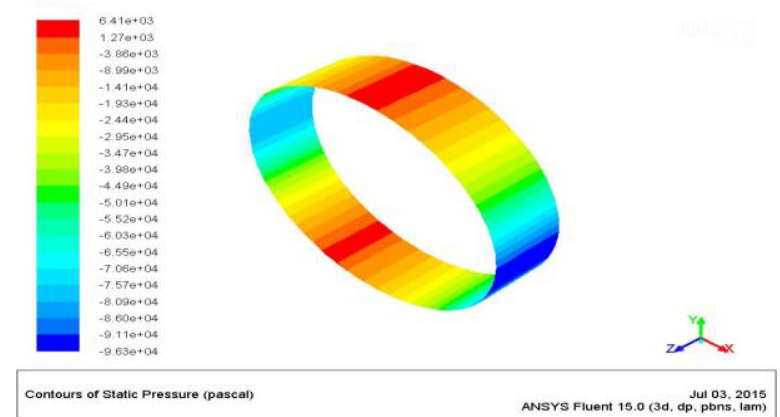

Figure-6. Static pressure contour of lubricant for 10000 rpm at laminar regime.

\section{Turbulent Approach}

Figures 7-12 depict the static pressure of the lubricant in the journal bearing by varying the rotational speed of 3000,5000 , and $10000 \mathrm{rpm}$ for turbulent analysis. In the present study, $k$-epsilon model is used to represent the turbulence. It can be observed that for the rotational speed of $3000 \mathrm{rpm}$ (see Figures 7 and 8), compared to the laminar pressure static, the analyzed score of pressure static using turbulent flow is lower. Most likely, this result comes from the presence of inertia. It is known that inertia is the most significant effect in contribution to make the lubricant very turbulent. Particularly from Figure 8, it can be concluded that the contour of the static pressure is more evenly distributed compared to the laminar flow.

The turbulent modelling approach for the rotational speed of $5000 \mathrm{rpm}$ (Figures 9 and 10) shows that the pressure static is the same with the rotational speed of $3000 \mathrm{rpm}$ turbulent. Similarly, the contours of pressure static are also more evenly distributed. Figures 11 and 12 indicate that the maximum pressure for the rotational speed of $10000 \mathrm{rpm}$ turbulent is a little bit higher compared to the lower rotational speed. Whereas, particularly from Figure 12, the contours are more similar to the contour predicted by that lower rpm.

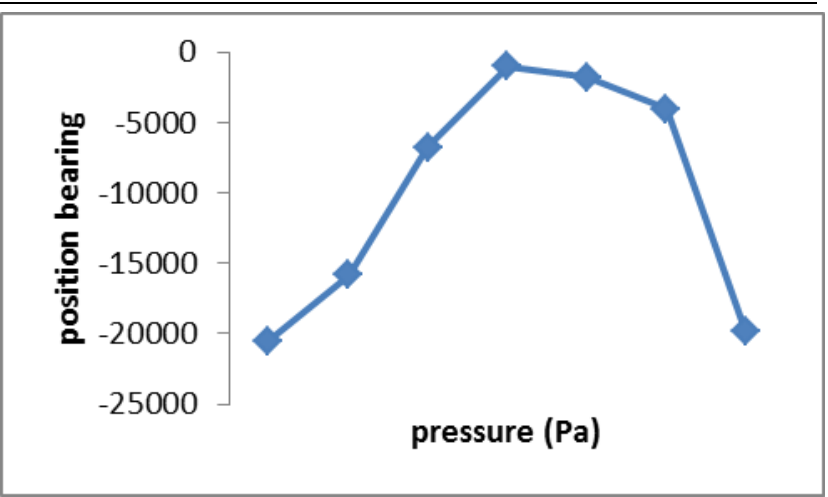

Figure-7. Static pressure distribution for turbulent condition at $3000 \mathrm{rpm}$.

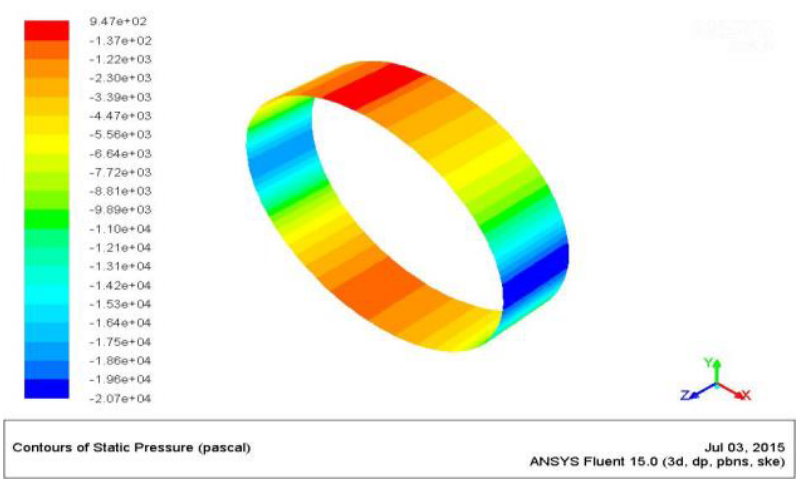

Figure-8. Static pressure contour of lubricant for 3000 $\mathrm{rpm}$ at turbulent regime.

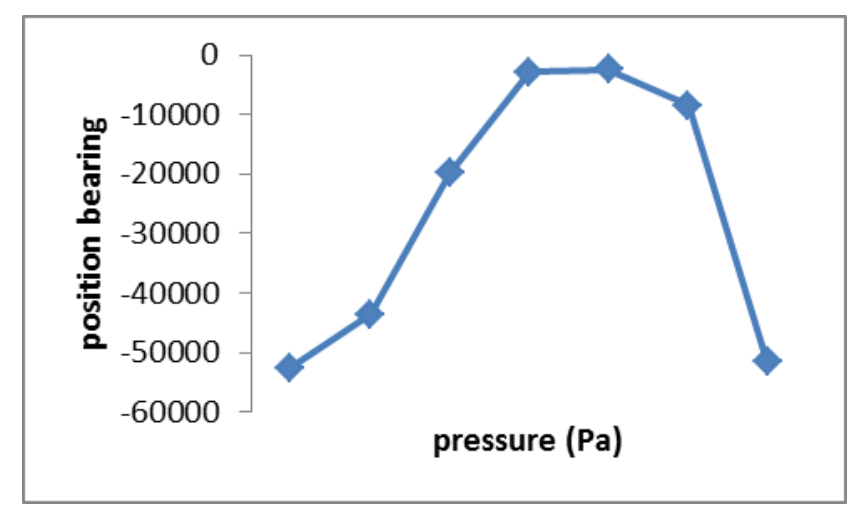

Figure-9. Static pressure distribution for turbulent condition at $5000 \mathrm{rpm}$.

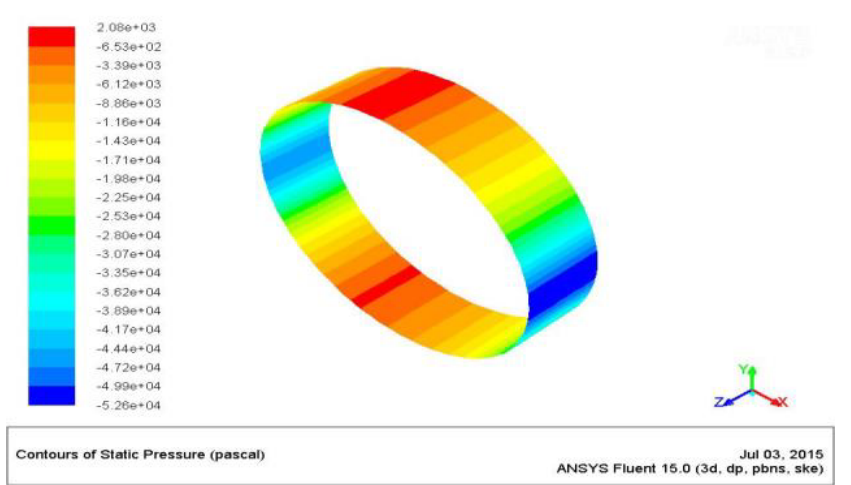

Figure-10. Static pressure contour of lubricant for 5000 rpm at turbulent regime. 


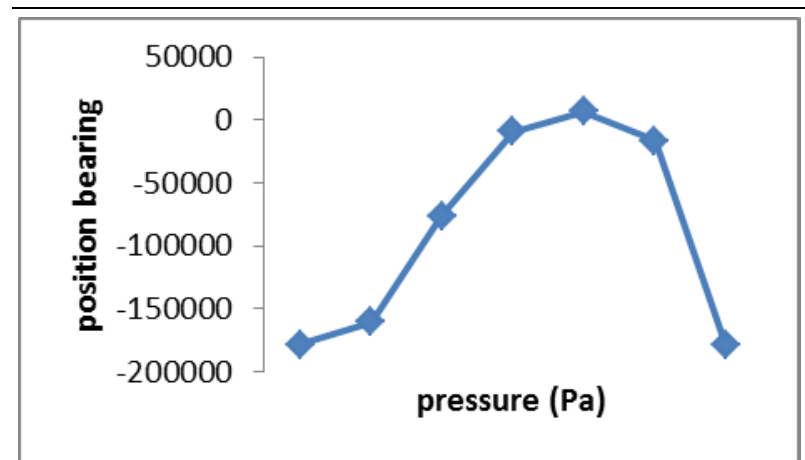

Figure-11. Static pressure distribution for turbulent condition at $10000 \mathrm{rpm}$.

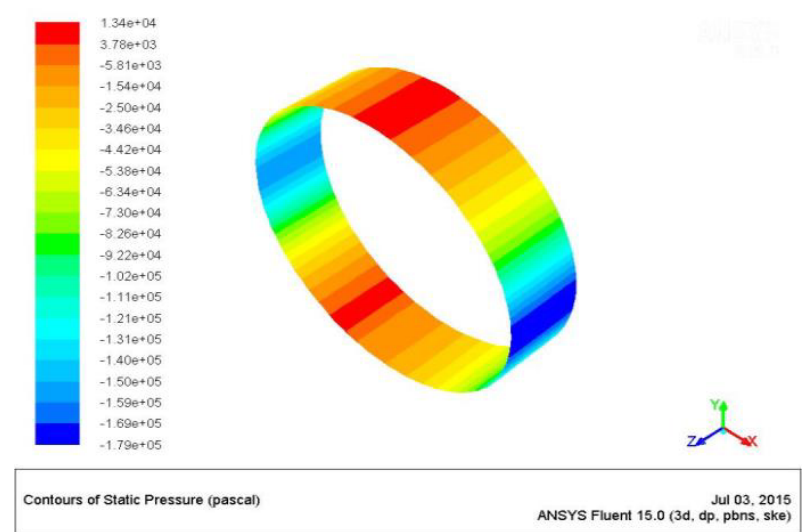

Figure-12. Static pressure contour of lubricant for 10000 rpm at turbulent regime.

\section{DISCUSSIONS}

As it is known, the journal bearing is one of the main components in the thermal fluid system. The load support can be generated by integrating the hydrodynamic pressure over the surface area. Further, this pressure generation can be analyzed by two different approaches, turbulent and laminar. In the real application, it is difficult to determine what appropriate model to use in analyzing the bearing characteristic. Therefore, the main contribution of this research is that by taking into account the cavitation effect, the turbulent as well as the laminar modelling is compared with respect to the hydrodynamic pressure.

From the overall analysis mentioned in the previous section, the distribution of static pressure shows the similar trend, which is: at the beginning, the pressure static is low, then, it gradually increases to the highest point, and finally drops significantly.

\section{CONCLUSIONS}

This paper presents the result of journal bearing simulation by using laminar and turbulent analyses. From the explanation, it can be concluded that both laminar and turbulent flows show the almost similar trend. It indicates that in the journal bearing, the turbulent effect can be ignored.

\section{REFERENCES}

Basri S. and Gethin D.T. 1990. A comparative study of the thermal behaviour of profile bore bearings.Tribology International, 23: 265-276.

Gertzos K.P., Nikolakopoulos P.G. and Papadopoulus C.A. 2008. CFD analysis Of journal bearing hydrodynamic lubrication by Bingham lubricant. Tribology International, 41: 1190-1204.

Gururajan K. and Prakash J. 2002. Roughness effects in a narrow porous journal bearing with arbitrary porous wall thickness. International Journal of Mechanical sciences, 44: 1003-1016.

Krasowski P. 2011. Velocity distribution in slide journal bearing gap by laminar unsteady lubrication. Journal of Kone Powertrain and Transport, 18(3): 177-184.

Murthy T.S.R., Balaramaiah Y. and Venkatesh V.C. 1983. An analysis of a special hydrodynamic bearing for machine tool spindles. Manufacturing Technology. 32(1): 319-325.

Panday K.M., Choudhury P.L. and Kumar N.P. 2012. Numerical Unsteady Analysis of Thin Film Lubricated Journal Bearing, 4(2) : 185-191.

Peng Y., Chen X., Zhang K. and Hou G. 2007. Numerical Research on water guide bearing of hydrogenerator unit using finite volume method. Journal of Hydrodynamics, 19: 635-642.

Radfordand A. and Fitzgeorge D. 1977. The effect of journal lobing on the performance a hydrodynamic plain journal bearing wear, 45: 311-322.

Roy L. 2009. Steady state thermo-hydrodynamic analysis and its comparison at five different feeding locations of an axial grooved oil journal bearing is obtained theoretically, Tribology International, 42(8) : 187-1198.

Sharma S., Satish C., Phalle., Vikas M. and Jain S.C. 2011. Performance analysis of a multirecess capillary compensated conical hydrostatic journal bearing. Tribology International , 44(5): 617-62.

Stefani F. and Rebora A. 2009. Steadily loadedjournal bearings:Quasi-3D mass-energy-conserving analysis. Tribology International, 42: 448-460. 